\title{
Shifting blue hue sign: an unusual endoscopic finding in a patient suspected of having gastrointestinal blood loss
}

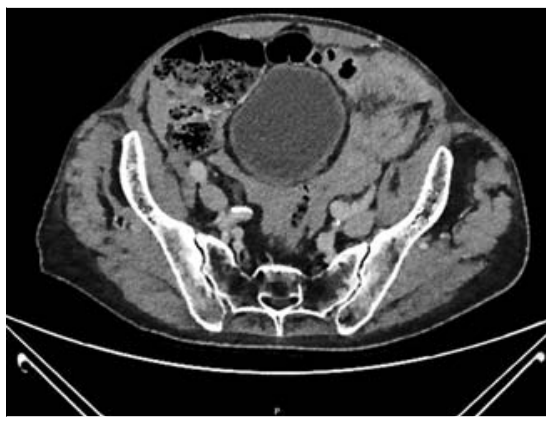

- Fig. 1 CT scan of the abdomen showing fluid in the peritoneal cavity with a Hounsfield unit value of approximately 60 , consistent with hemoperitoneum.

A 75-year-old man presented to the emergency department with lower abdominal pain for 4 days. He had a history of atrial fibrillation for which he used rivaroxaban. He did not report any trauma. He mentioned that he had black tarry stools. His vital signs were normal. Physical examination showed some tenderness in the lower abdomen. Rectal examination was not performed. His hemoglobin had dropped to $10.6 \mathrm{~g} / \mathrm{dL}$.

We performed an esophagogastroduodenoscopy but did not identify a cause for the black stools. We then performed a colonoscopy with intubation into the cecum. We did not observe any lesions causing melena. However, we did note a bluish discoloration through the mucosa scattered with areas of normal-colored colon. The bluish hues of varying shapes and sizes were seen throughout the colon except for the rectosigmoid. When we pressed on the patient's abdomen or changed his position, the shapes and areas of the configurations shifted $(\triangleright$ Video 1 ). Because of the shifting blue hue sign, we suspected an intraperitoneal hemorrhage. We therefore performed a

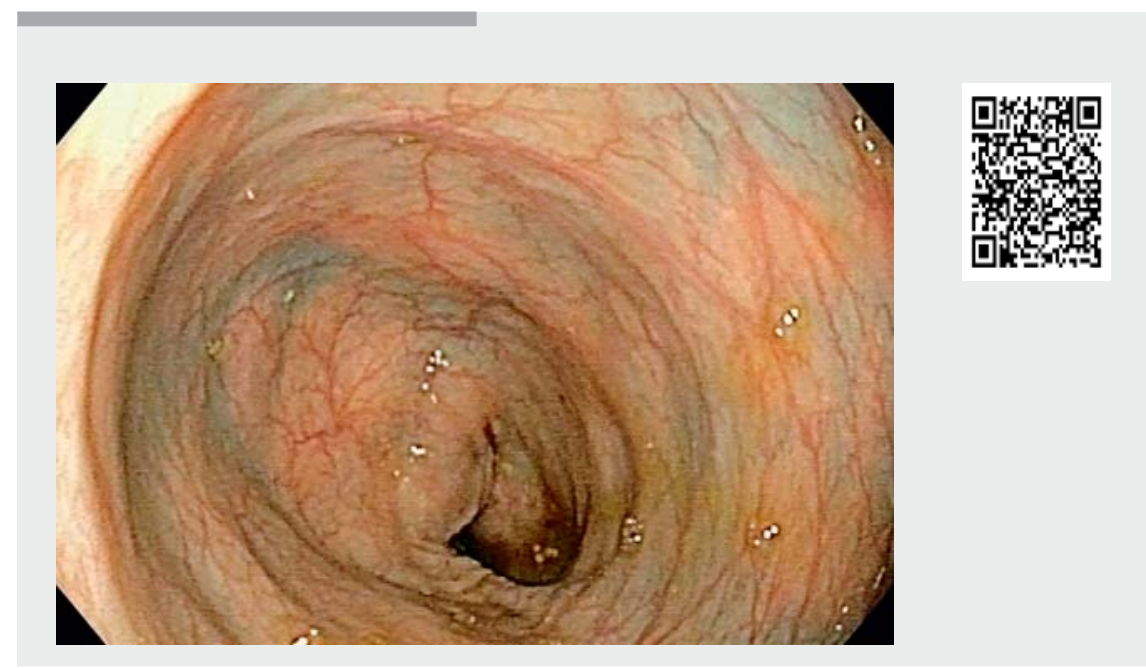

Video 1 During colonoscopy, multiple blue hue configurations were seen. Pressing on the patient's abdomen or changing his position caused shifting of the shapes and areas.

CT scan ( $>$ Fig. 1), which confirmed our suspicion but did not point to a specific cause of the hemorrhage. Because the patient remained hemodynamically stable, we treated him conservatively and temporarily discontinued rivaroxaban.

This case shows that if a shifting blue hue sign is observed during colonoscopy, an intraperitoneal hemorrhage should be suspected. To the best of our knowledge, only three cases have been described matching our case [1-3]. However, a video of the changing blue hue appearance, which we believe is necessary to document the signs of shifting, has never been published. When a shifting blue hue sign is encountered, we recommend performing a CT scan to confirm an intraperitoneal hemorrhage and treating accordingly.

Endoscopy_UCTN_Code_CCL_1AD_2AI

\section{Competing interests}

None

The authors

Mark P. Lamberts, Helena T. J. I. de Leest Department of Gastroenterology and Hepatology, Rijnstate Hospital, Arnhem, The Netherlands

\section{Corresponding author}

\section{Mark P. Lamberts}

Rijnstate Hospital, 6815 AD, Arnhem, The Netherlands

Fax: +31880057506

Marklamberts@hotmail.com 


\section{References}

[1] Parithivel VS, Rosario PG, Subbarao M. Shifting blue hue sign. Gastrointest Endosc 1990; 36: 422

[2] Kan EY, Wong LM. Massive occult haemoperitoneum following spontaneous rupture of duodenal gastrointestinal stromal tumour. Australas Radiol 2007; 51: B130-2

[3] Park DY, Moon W. Simultaneous occurrence of obscure-overt gastrointestinal and intraperitoneal bleeding in gastrointestinal stromal tumor. Clin Gastroenterol Hepatol 2010; 8: A28

\section{Bibliography}

DOI https://doi.org/10.1055/a-1045-4161

Published online: 9.12.2019

Endoscopy 2020; 52: E183-E184

(c) Georg Thieme Verlag KC

Stuttgart · New York

ISSN 0013-726X

\section{ENDOSCOPY E-VIDEOS}

https://eref.thieme.de/e-videos

Endoscopy E-Videos is a free access online section, reporting 口. on interesting cases and new techniques in gastroenterological endoscopy. All papers include a high quality video and all contributions are freely accessible online.

This section has its own submission website at

https://mc.manuscriptcentral.com/e-videos 